\title{
REUSE OF RECLAIMED MATERIAL IN ROAD CONSTRUCTION LAYERS
}

Petr MONDSCHEIN ${ }^{1 *}$

\begin{abstract}
The paper summarizes past experience in the use of reclaimed material in road construction layers according to various technologies applied in road construction. The recycling of asphalt pavements is a standard widely applied and established in road practice for many years. There is strong interest to increase the use of recycled materials in asphalt pavements for cost and environmental reasons. The paper defines the strengths and weaknesses of individual technologies and recommends where and when the use of $R$-material is appropriate, economically sound and technically justified. The production of new asphalt mixes with more reclaimed material is limited by more factors in the Czech Republic. They include the regulation of the quantity of reclaimed material in the standards and technical regulations. The machine equipment of contractors for recycling is not always sufficient either.
\end{abstract}

\section{Address}

1 Czech Technical University in Prague, Faculty of Civil Engineering, Department of Road Structures

* Corresponding author: petr.mondschein@fsv.cvut.cz

\section{Key words}

- Recycling technologies,

- Road construction materials.

\section{INTRODUCTION}

Despite the fact that road construction is considered a low-tech branch with no recent breakthroughs or astounding developments, there are changes and progress manifested in this area that are responding to the conditions and stimuli of modern times. It is, therefore, not surprising that road construction technologies have undergone significant developments over the past few decades.

The current political striving for sustainable development has become a major impetus for the search for new trends.

The European Long-Term Strategic Plan, which has been implemented in various modifications in national strategic policies, laid down several key areas in the late 1990s where new developments were needed: reducing emissions, reducing working temperatures, reducing energy consumption (energy performance), improving the workability of mainly asphalt mixes, while respecting the above goals, seeking new recycling options, extending the service life of technologies, and reducing the need for their remediation, effectively increasing resistance to the effects of growing traffic volumes and climate impacts, finding alternative (renewable) resources, and conscientiously protecting natural resources.

One of the above-mentioned issues is the search for new recycling options for materials used in road construction layers. The benefits of reusing materials are well known, so this paper is not meant to enumerate them. An important aspect of recycling is the realization of how a material's life cycle is running as is shown in Figure 1. In the Czech Republic, we are still looking for possibilities of how to reuse materials reclaimed from road construction, but we also need to look into a more distant future when a situation may arise that we will recycle material previously recycled under the same boundary conditions, or that we may be technically limited in reusing material that has gone through one or multiple recycling processes (Valentová et al., 2016).

Given its size, this paper cannot describe all the recycling options available in road construction, so it is focusing solely on the reuse of socalled R-material, which is defined in (ČSN EN 13108-8, 2008) as a bitumen mix reclaimed by milling off asphalt pavement layers or by crushing slabs removed from asphalt pavements or large chunks of an asphalt mix 


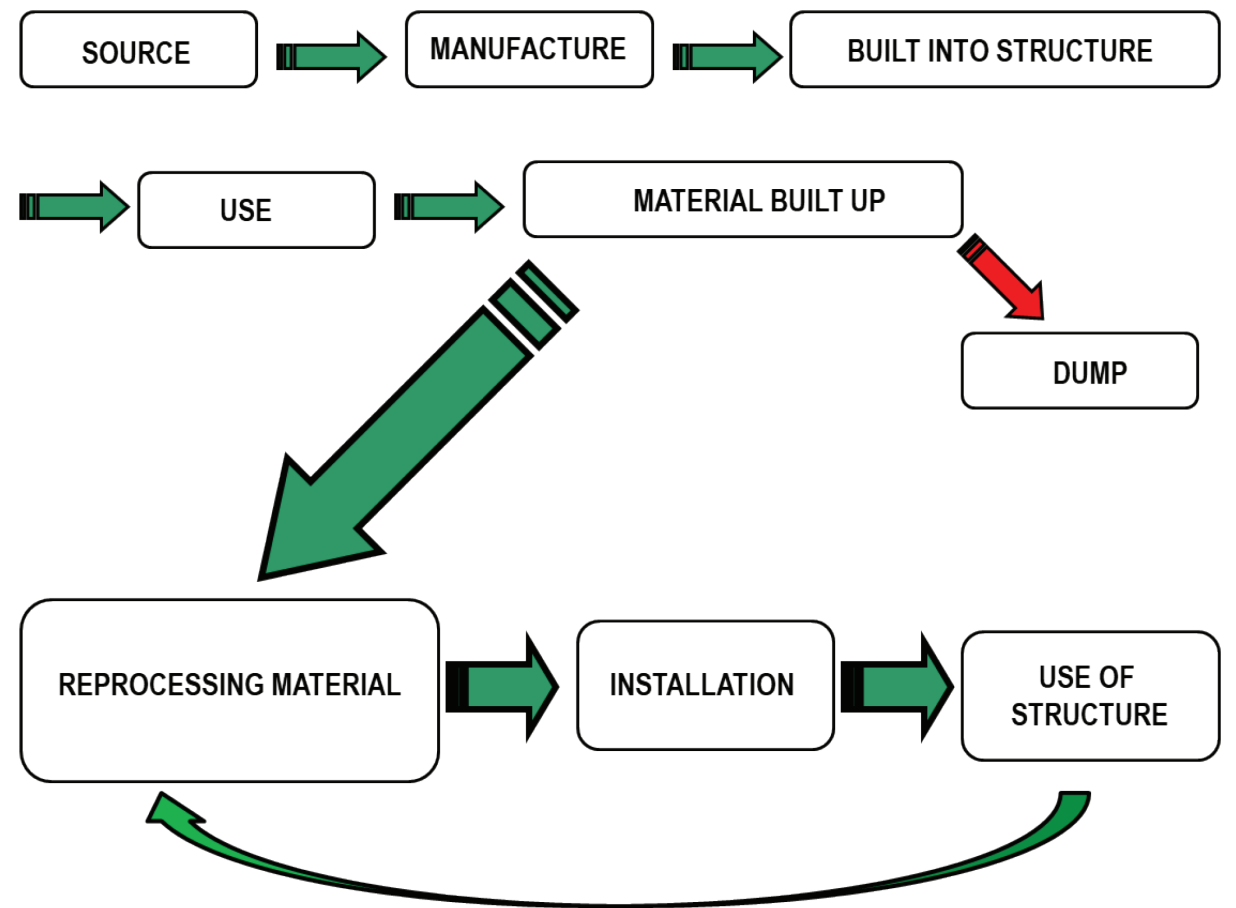

Figure 1: Life cycle of materials

and asphalt mixes from faulty or excess production. It is, therefore, a material that only consists of aggregates and an asphalt binder, it should not be confused with so-called recycled asphalt. The TP 210 Code (2011) allows R-material to contain less than $5 \%$ of other recycled materials.

From a long-term perspective, it is possible to trace a steady rise in oil prices as far as derivatives are concerned. The recycling of milled or burnt material from compacted asphalt layers is therefore a prerequisite for the responsible management of natural resources such as aggregates and bituminous binders. The processing of reclaimed material into hot asphalt mixtures is the most efficient use of this material. Comparing the Czech Republic to Western European countries, it is not on the same level. There is the same/similar situation in the Czech Republic as in Slovakia (Capayova et al., 2015).

Using R-materials results in savings in terms of material, energy and natural resources in Canada and the United States of America. It is estimated that 68.3 million tons of R-material were consumed in North America in 2012, thereby saving 3.4 million tons of binders and \$ 2 billion (Hansen et al., 2013). In 2015, approximately 69.7 million tons of R-material were consumed in the United States (EAPA, 2017). The largest producer of reclaimed material in Europe is Germany (11 million tons), followed by France (7 million tons) (EAPA, 2017).

The paper analyzes technical options for using asphalt R-Material for the production of new hot asphalt mixes, its recycling potential, and the motivation for use. In the Czech Republic, the recycling trend is theoretically supported and enforced in the highest political circles. In practice, however, this technology, and not only asphalt mix technology, but also recycling in cement-concrete technologies, faces considerable obstacles on the part of investors, who still question its quality. Moreover, contractors in the Czech Republic are forced to buy milled-off material from investors at such high prices that the contractors' investments in new technologies are paid back very slowly.

\section{R-MATERIAL}

R-material is denoted by the general label "U RA d/D", where the letter $U$ specifies the maximum size of the coated grain, and the
d/D fraction specifies the grain size of the aggregate mixture contained in the R-material (ČSN EN 13108-8, 2008). It is also common to describe R-material by its volume density, the amount of asphalt binder, and its basic empirical characteristics, i.e., its softening point and penetration (ČSN EN 13108-20, 2008). However, this information is insufficient for some methods for the further use of R-material. Another necessary characteristic that must be known for the effective use of R-material is knowledge of the type or modification of the bitumen binder. For the most part, there is no property passportization available for our roads, where the sort and type of asphalt mix can be traced even over a long-term time horizon when repairs or regular replacements of the wearing course have been carried out. For these reasons, it is necessary to determine the modification or non-modification of the bituminous binder, which can very well be done using reversible and force ductility or measurements with DSR devices or spectrometers.

R-material can be used in all standard technologies: unbound layers, cold recycling technology performed on-site or in a mixing centre, or asphalt mix production with the addition of R-material to a hot mix in an asphalt batching plant. The first option, which is frequently used by designers when R-material is used in unbound base courses of roads or as backfill of unpaved shoulders, is totally inappropriate and cannot exploit the high potential of the material. It also causes implementation problems of which investors and designers are not always aware. The use of R-material as a substitute for crushed gravel and mechanically consolidated aggregate technology is allowed by the Code (TP 208, 2009); further motivation for such use is found in the Catalogue constructions listed in (TP 170, 2004). In the event of an inexpensive source of R-material, an option for reusing reclaimed R-material becomes obvious without the necessity of special technological equipment and special knowledge on the contractor's part.

In the past, R-material generally served as crushed gravel on forest and field roads where it represented the topmost wearing course of a road construction, thereby ensuring its dust-free surface and some driving comfort for road users. In the summer, at higher temperatures, the road surface was additionally compacted and enclosed by traffic, so the porosity of the construction layer was reduced. Thanks to the 
Table 1 Overview of asphalt mixes produced in the Czech Republic from 2010 to 2016 (Road Builders'Association, 2016)

\begin{tabular}{|c|c|c|c|c|c|c|c|}
\hline Year & 2010 & 2011 & 2012 & 2013 & 2014 & 2015 & 2016 \\
\hline Total asphalt mix production in ths. tons & 5,897 & 5,617 & 5,459 & 5,152 & 6,083 & 7,682 & 6,402 \\
\hline ACO in ths.tons & 2,990 & 3,033 & 2,876 & 2,668 & 3,047 & 3,871 & 3,066 \\
\hline ACL and ACP in ths. tons & 2,459 & 2,162 & 2,085 & 1,998 & 2,536 & 3,149 & 2,656 \\
\hline Other mixes in ths. tons & 448 & 422 & 498 & 486 & 500 & 662 & 680 \\
\hline
\end{tabular}

Table 2 Detailed overview of asphalt mixes produced in 2016(Road Builders'Association, 2016)

\begin{tabular}{|c|c|c|c|c|c|c|c|c|c|c|}
\hline Asphalt mix type & ACO & ACL and ACP & BBTM & SMA & LA & PA & AKO & VMT & SAL & $\begin{array}{c}\text { Noise- reducing } \\
\text { asphalt mixes }\end{array}$ \\
\hline Production in ths. tons & 3,066 & 2,656 & 20 & 394 & 41 & 2 & 20 & 142 & 27 & 34 \\
\hline
\end{tabular}

Road Pavement Catalogue in (TP 170, 2004), R-material is currently used in the base courses of roads with lower traffic volumes. However, cold laid R-material is not fully compacted on these roads, so in the summer months, when this layer is heated to a relatively high temperature, the construction layer of R-material will exhibit creep that results in successive permanent deformations of the road surface.

Cold recycling technology, which is performed on-site or in a mixing centre and which uses solely $100 \%$ R-material, is less common. It requires roads to have a minimum bitumen-bound thickness of approximately $250 \mathrm{~mm}$. The general principle is to maintain the existing road level or to increase it by no more than $50 \mathrm{~mm}$. To lay a new asphalt cover, at least $120 \mathrm{~mm}$ of the existing bitumen-bound layers must be milled off; subsequently, at least $120 \mathrm{~mm}$ of construction layers must be recycled (the standard thicknesses are a newly laid bitumen-bound multilayer of $150 \mathrm{~mm}$, recycling of $180 \mathrm{~mm}$ with a total thickness of $330 \mathrm{~mm}$ ). The advantage of such use is the application of homogeneous material with a resulting high quality and functionality of the newly laid recycled layer. The application of this technology is suitable for such materials as bitumen-coated gravel sand, bitumen-coated crushed gravel or bitumen-coated coarse-grained aggregate types; these are no longer compatible with currently produced asphalt mixes.

\section{HOT RECYCLING IN AN ASPHALT BATCHING PLANT}

The only way to maximize the potential of R-material is its "hot reprocessing" in an asphalt batching plant during the production of new asphalt mixes. The situation regarding the use of R-material in asphalt mixes in the Czech Republic is unclear. It is unclear in terms of how this use is allowed by the technical regulations and legislation and how the use of R-material in this technology is accepted by the professional (but more likely the investor part of the professional) public. Table 3 gives an overview of possible additions of R-material in newly-produced mixes in the present and future following an upcoming review of the standards.

The table below indicates that R-material cannot presently be used in the wearing courses of roads with a higher proportion of heavy freight traffic that use S-grade asphalt concretes. In the future, there will be a slight improvement, where at least $20 \%$ of R-material will be allowed in SMA type mixes. The comparison of the current state with the future implies that a growth in the use of R-material by approximately $10-30 \%$ will be allowed.

About 6,000 ths. tons of asphalt mixes are annually produced in the Czech Republic. The overview of mixes produced from 2010 to 2016 is presented in Table 1. A detailed overview of the mixes produced in 2016 is presented in Table 2 . The figures imply that the repair trend, which consists of the mere replacement of a wearing
Table 3 Admissible amounts of R-material added to newly produced asphalt mixes

\begin{tabular}{|c|c|c|}
\hline \multirow[t]{2}{*}{ Asphalt mix } & \multicolumn{2}{|c|}{$\begin{array}{c}\text { Highest admissible R-material content in } \% \\
\text { of asphalt mix weight }\end{array}$} \\
\hline & under standards in force & design \\
\hline $\mathrm{ACO} 8$ & 25 & 35 \\
\hline $\mathrm{ACO} 8 \mathrm{CH}$ & 25 & 35 \\
\hline ACO $11 \mathrm{~S}$ & 0 & will not exist \\
\hline $\mathrm{ACO} 11+$ & 0 & 30 \\
\hline ACO 11 & 25 & 35 \\
\hline $\mathrm{ACO} 16 \mathrm{~S}$ & 0 & will not exist \\
\hline $\mathrm{ACO} 16+$ & 0 & 30 \\
\hline ACO 16 & 25 & 35 \\
\hline ACL $16 \mathrm{~S}$ & 30 & 40 \\
\hline ACL $16+$ & 30 & 50 \\
\hline ACL 16 & 40 & 50 \\
\hline ACL $22 \mathrm{~S}$ & 30 & 40 \\
\hline ACL $22+$ & 30 & 50 \\
\hline ACL 22 & 40 & 50 \\
\hline ACP $16 \mathrm{~S}$ & 50 & 60 \\
\hline ACP $16+$ & 60 & 70 \\
\hline ACP $22 \mathrm{~S}$ & 50 & 60 \\
\hline $\mathrm{ACP} 22+$ & 60 & 70 \\
\hline VMT & 30 & 30 \\
\hline BВTM & 0 & 0 \\
\hline SMA & 0 & 20 \\
\hline
\end{tabular}

course and which is not always the ideal solution, still prevails in the Czech Republic. This aspect, however, is not the topic of this paper.

If we identify the potential of R-material for use in asphalt mixes allowed by the legislation, we arrive at approximately 1,835 ths. tons of R-material that can be put into production. After legislative changes, this figure will come up to around 2,660 ths. tons of R-material. In terms of financial indicators, it will represent approximately 0.4 billion CZK per year, which is an amount that should motivate the companies specializing in development and innovations of recycling technology.

The use of such high contents of R-materials in mixes has been 
verified within SFDI New Technology projects. In 2012, a test section was made on the II/204 Mrtník - Kaznějov road (Mondschein, 2013), while in 2013, there were two test sections on II/235 Terešov - Terešovská Hut' and the II/233 Prašný újezd - intersection with III/23317 (Mondschein et al., 2014). In these sections, asphalt mixes were laid onto the wearing courses with $40 \%$ of R-material, and mixes with $75 \%$ of R-material were applied on the binder and base courses. The roads show no defects caused by the use of R-material even after four or five years.

\subsection{MANUFACTURING PLANTS}

There are three basic technological options for the production of hot-mix asphalt mixes with R-material contents in an asphalt batching plant, if we leave out continuous asphalt plants, which are represented minimally or not at all in the Czech and Slovak Republics.

The options involve the addition of R-material to a cold mix, the double barrel drum mix technology, and the parallel flow drum mix technology. The only correct method with no technological limitations is the use of a second drum in an asphalt batching plant where the R-material is heated to a temperature of approximately $120^{\circ} \mathrm{C}$ or higher.

The cold mix technology permits the addition of approximately $20 \%$ of R-material in the production process. Some manufacturers state that under ideal conditions, when R-material is dry, up to $30 \%$ of R-material can be added. Generally, it is always problematic to maintain the homogeneity of the added R-material in the production; therefore, some asphalt batching plants are equipped with two cold containers for R-material, so that they can compensate for fluctua- tions in quality by the additional homogenization of the raw material input in the dosing phase.

Double barrel dryer/drum mixers with a middle ring, which are able to add up to $50 \%$ of R-material in production, have been introduced into the Czech market. This technology is cheaper by several times than a parallel flow drum, but it has technological limitations, which can negatively affect the quality of the mixes produced. This risk does not result from the production technology itself, but from the poor quality of the raw materials input, i.e., the poor quality of aggregates. The double barrel dryer/drum mix production, in fact, does not apply a hot sorting technology, but all the heated material enters directly into the mixing process. Therefore, this technology is sensitive to the quality (grain size) of the asphalt mix components input. Some asphalt mix manufacturers also use a combination of a double barrel drum mixer with a cold mix technology, which allows them to increase the content of the R-material added. Then, low-temperature or low viscosity additives are recommended for use in these technological steps to allow them to maintain the existing mixing times or extend them only slightly; there is therefore no significant loss in the plant's performance.

\section{RECYCLING MANAGEMENT}

The main objective in the production of asphalt mixes using R-material is the preservation of the quality at the output, i.e., the mixes produced must have identical empirical and functional properties as asphalt mixes made entirely from new components. The manufacturer must have a system that ensures a high production standard. The basic rule should be selective milling and subsequent dumping

Table 4 Characteristics of $R$-material samples

\begin{tabular}{|c|c|c|c|c|c|c|}
\hline \multirow{3}{*}{ Sieve in $\mathrm{mm}$} & \multicolumn{2}{|c|}{ R-material $\mathrm{K}$} & \multicolumn{2}{|c|}{ R-material S } & \multicolumn{2}{|c|}{ R-material R } \\
\hline & \multicolumn{2}{|c|}{ Total undersize in $\%$} & \multicolumn{2}{|c|}{ Total undersize in $\%$} & \multicolumn{2}{|c|}{ Total undersize in $\%$} \\
\hline & R-material & Aggregate mix & R-material & Aggregate mix & R-material & Aggregate mix \\
\hline 32 & 100 & 100 & 100 & 100 & 100 & 100 \\
\hline 22.4 & 100 & 100 & 100 & 100 & 93 & 99 \\
\hline 16 & 99 & 100 & 100 & 100 & 84 & 96 \\
\hline 11.2 & 88 & 95 & 90 & 93 & 75 & 90 \\
\hline 8 & 69 & 83 & 68 & 78 & 63 & 83 \\
\hline 5.6 & 45 & 64 & 49 & 60 & 50 & 72 \\
\hline 4 & 29 & 50 & 34 & 47 & 39 & 62 \\
\hline 2 & 9 & 30 & 14 & 32 & 21 & 44 \\
\hline 1 & 4 & 21 & 6 & 24 & 10 & 30 \\
\hline 0.5 & 3 & 16 & 4 & 18 & 5 & 21 \\
\hline 0.25 & 1 & 12 & 2 & 14 & 2 & 15 \\
\hline 0.125 & 1 & 9 & 1 & 11 & 1 & 11 \\
\hline 0.063 & 0 & 7 & 0 & 7 & 0 & 8 \\
\hline Binder content in $\%$ & --- & 5.4 & --- & 4.7 & --- & 5.4 \\
\hline Specific surface a. $\mathrm{m}^{2} \cdot \mathrm{kg}^{-1}$ & --- & 11.03 & --- & 17.21 & --- & 17.22 \\
\hline Film thickness in $\mathrm{mm}$ & --- & 0.0051 & --- & 0.0028 & --- & 0.0032 \\
\hline Penetration in $\mathrm{mm} 10^{-1}$ & --- & 23 & --- & 18 & --- & 41 \\
\hline Softening point in ${ }^{\circ} \mathrm{C}$ & --- & 61.6 & --- & 61.6 & --- & 55.6 \\
\hline
\end{tabular}


of the reclaimed material. The milled material should be crushed and sorted by a special technology, where grains will not be broken but only separated from each other.

Ensuring the proper asphalt mix behaviour, i.e., the rejuvenation of the asphalt binder's properties, is a separate issue and a topic for another paper. Again, there are several options, e.g., the use of soft asphalt binders or rejuvenators. Each of these technological operations has its own pitfalls and positive aspects. However, manufacturers who do not modify R-material and thus devalue the acceptance of this technology cannot be tolerated.

As a small example, Table 4 lists the characteristics of three different R-materials sampled from three batching plants engaged in the production of asphalt mixes with higher R-material contents on a long-term basis. The illustrative comparison shows that the R-material characteristics significantly differ. This results from the type of recycled mix, its composition, age, and other aspects. It only supports the necessity of the existence of appropriate knowledge, a system, and rules for using R-material.

The existence of a "passport" for road constructions, which would clearly state what types of asphalt mixes were used during the construction and repairs, would be of significant benefit. In this case, it would be possible for the contractor to limit some of the performed tests and ensure the administratively sufficient homogeneity of the input material.

\section{CONCLUSION}

The information presented summarizes the hot recycling technology at a plant in the Czech Republic. The main trend of this technology is to increase the proportion of reclaimed material in newly produced asphalt mixtures. There is now a surplus of material in the Czech Republic, so its potential is not being exploited sufficiently. The main obstacles to increasing the proportion of reclaimed material in production are legislative constraints and the technological readiness of contractors. Asphalt mixtures with a high proportion of reclaimed material can be technically manufactured, but it is necessary to adhere to the technological principles and rules that ensure the required quality of the products, construction layers, and road construction. Otherwise, investors will not support the hot recycling technology at a mixing plant.

On the other hand, investors and road owners should give more freedom to the manufacturers and leave the production and application of mixtures with a higher R-material proportion in the construction and reconstruction of roads up to them. The investors should start by formulating projects where they will prescribe how much material the contractors are obliged to reuse in the construction. This is the fastest way they can boost technological development.

\section{REFERENCES}

Capayova, S. - Zuzulova, A. - Bacova, K. (2015) Properties of asphalt mixtures with reclaimed material in Slovakia. In: Green Building, Materials and Civil Engineering: selected papers from the 4th International Conference on Green Building, Materials and Civil Engineering (GBMCE), Hong Kong, China, 21. - 22. 8. 2014. 1st ed. London: CRC Press, Taylor \& Francis Group, pp. 17-20. ISBN 978-1-138-02669-8. SCOPUS, Code 123669.

Copeland, A. (2011) Reclaimed Asphalt Pavement in Asphalt Mixtures: State of the Practice, FHWA-HRT11-021, U.S. Department of Transportation, Federal Highway Administration (FHWA), Office of Infrastructure Research and Development, McLean, VA, available on https://www.fhwa.dot.gov/publications/research/ infrastructure/pavements/11021/11021.pdf

ČSN EN 13108-20 (2008) Asphalt Mixes - Specifications for Materials - Part 8: Type Tests, UNMZ, Prague, Czech Republic

ČSN EN 13108-20 (2008) Asphalt Mixes - Specifications for Materials - Part 20: Type Tests, UNMZ, Prague, Czech Republic

EAPA (2017) Asphalt in Figures 2015, European Asphalt Pavement Association, available on http://www.eapa.org/userfiles/2/Asphalt\%20in\%20Figures/2016/AIF_2015_v6.pdf

Hansen, K. R. - Copeland, A. (2013) Annual Asphalt Pavement Industry Survey on Recycled Materials and Warm-Mix Usage: 2009-2012, NAPA Information Series 138, available on https:// www.asphaltpavement.org/PDFs/IS138/IS138-2012_RAP-RASWMA_Survey_Final.pdf.
Mondschein, P. (2013) Test Section II/204 Mrtník - Kaznějov, In: Silnice mosty $2 / 2013$, pp. 12-14

Mondschein, P. - Svoboda, P. - Valentin, J. (2014) Assessment of Test Sections with Application of Increased Amounts of R-material and Asphalt Foam in Hot Mixes, In: Silnice mosty, 4/2014, Pragoprojekt, a. s., pp. 56-58, ISSN 1804-8684

Road Builders' Association, Production and Processing of Materials for Road Construction in 2016

TP 210 (2011) Using Recycled Building Demolition Materials in Roads, Ministry of Transport of the Czech Republic, Brno University of Technology, Czech Republic

TP 208 (2009) Cold Recycling of Construction Layers of Non-Rigid Pavements, Ministry of Transport of the Czech Republic - OSI

TP 170 (2004) Design of Road Pavements, Ministry of Transport of the Czech Republic

Valentová, T. - Kotoušová, A. - Simnofske, D. - Valentin, J. - Mollenhauer, K. (2016) Properties of Asphalt Mixtures with Multiple Recycled Asphalt Material, In: Geotechnical Special Publication, Vol. 2016-Jan., No 262 GSP, 2016, 4th Geo-China International Conference on Innovative and Sustainable Solutions in Asphalt Pavements, Geo-China 2016; Shandong; China; 25 - 27 July 2016; Code 122995 pp. 1-10, ISSN: 08950563, SCOPUS, DOI: 10.1061/9780784480052.001 